\title{
The Current Status and Challenges of National Smoking Cessation Support Program in Korea
}

\author{
Seung-Won $\mathrm{Oh}^{*}$ \\ Department of Family Medicine, Seoul National University Hospital Healthcare System Gangnam Center, Seoul, Korea
}

\section{See original paper on 373}

Smoking is a chronic disease that requires repeated interventions. According to the World Health Organization, 450 million deaths will be caused by smoking over the next 50 years. ${ }^{1)}$ Screening all patients who use tobacco to provide intervention to quit smoking is one of the most important forms of prevention in primary care. Physicians can help smokers quit by assessing their dependence and motivating them during their clinic visits. Brief advice provided by doctors is a simple and very cost-effective method of smoking cessation. The most effective method of helping smokers quit is through combining pharmacotherapy with counseling and behavioral interventions.

The Framework Convention on Tobacco Control (FCTC), which was adopted from February 2005, is an international agreement in the field of global health, which includes topics such as measures to reduce tobacco demand, measures to reduce tobacco supply, institutional arrangements, and resources. Over 180 countries are adhering to this agreement. According to the 2014 Global Progress Report of the FCTC, 95 countries have included smoking cessation treatment in their national health systems. Many countries encourage participation in treatment based on outpatients and hospitals. ${ }^{2)}$ The UK National Health Service started to provide pharmaceutical treatments and behavioral support for all tobacco users in 2000. The United States has been providing smoking cessation counseling and drug treatment since 2014 under the Patient Protection and Affordable Care Act. Japan, Taipei, Canada, and Australia also provide clinic-based smoking cessation services, which include both counseling and pharmaceutical treatment.

In early 2015, the National Health Insurance Service of Korea started a smoking cessation support program that covered counseling and medication. More than 400,000 smokers registered in this program and received assistance from health care providers in 2017. The program consisted of up to 18 medical counseling consultations for up to 36 weeks and support for the cost of administering anti-smoking drugs (nicotine substitutes such as nicotine patches, gum, lozenges, and two oral medications). The success rate at 6 months was approximately $40 \%$, which is comparable with that of smoking cessation clinics run by local public health centers. ${ }^{3)}$

In the present issue, Yu et al. ${ }^{4)}$ investigated the success rate of smoking cessation and risk of relapse after implementation of the national smoking cessation support program. Results indicated that a 6-month success rate of smoking cessation was $64.8 \%$, which was higher than the rate in a 2016 survey. The authors suggest this difference may have been caused by professional intervention and drug treatment by a physician. In the previous study, the smoking cessation rate of the registrants using the advanced general hospital was also higher than that of the registrants using the local clinic. ${ }^{3)}$ According to Yu et al., ${ }^{4)}$ higher medication compliance was associated with a lower risk of primary failure, and more frequent visits to smoking cessation clinics were associated with a lower risk of relapsing. More than half of all registrants were known to have dropped out after one or two visits. Considering the results of this study, it is important to have a plan for the participants to visit continuously. The number of participants in the program has increased steadily from 2015 to 2017, but has plummeted 
in 2018, according to a recent media report. ${ }^{5)}$ This may be attributed to the combination of the launch of e-cigarettes at the end of 2017, rising smoking rates, and low medical fees for smoking cessation counseling. Considering the high cessation rate of the program, the strategy to increase the enrollment rate is also important.

\section{CONFLICT OF INTEREST}

No potential conflict of interest relevant to this article was reported.

\section{ORCID}

Seung-Won Oh: https://orcid.org/0000-0003-3800-0754

\section{REFERENCES}

1. Gellert C, Schottker B, Brenner H. Smoking and all-cause mortality in older people: systematic review and meta-analysis. Arch Intern Med 2012;172:837-44.

2. Choi EY, Cho HJ, Lee JA, Lee JY, Jung HM, Ock M, et al. Current status of smoking cessation program in foreign countries. J Korean Soc Res Nicotine Tob 2016;7:53-60.

3. Paek YJ, Choi JK, Lee ES, Jo MW. Smoking cessation services provided by the National Health Insurance Service. J Korean Med Assoc 2018;61:157-62.

4. Yu SH, Kim MJ, Jeon J, Park HK, Hwang HS, Park KY. Short-term success rates of smoking cessation support programs and factors predicting smoking relapse: using data from a smoking cessation clinic in a hospital. Korean J Fam Med 2019;40:373-9.

5. Shin HJ. Will there be plans to improve the support for smoking cessation treatment in medical institutions? [Internet]. Seoul: Medical Observer; 2019 [cited 2019 Nov 12]. Available from: http://www.monews. co.kr/news/articleView.html?idxno=202452. 